Article

\title{
Association of Two Indices of Insulin Resistance Marker with Abnormal Liver Function Tests: A Cross-Sectional Population Study in Taiwanese Adults
}

\author{
Adi-Lukas Kurniawan ${ }^{1, *(D)}$, Chien-Yeh Hsu ${ }^{2,3}$, Jane C.-J. Chao ${ }^{3,4,5, *(D)}$, Rathi Paramastri ${ }^{4}$ (D), Hsiu-An Lee ${ }^{6,7}$ (iD) and \\ Amadou-Wurry Jallow ${ }^{8}$ (D)
}

1 Research Center for Healthcare Industry Innovation, National Taipei University of Nursing and Health Sciences, 365 Ming-te Road, Beitou District, Taipei 112, Taiwan

2 Department of Information Management, National Taipei University of Nursing and Health Sciences, 365 Ming-te Road, Beitou District, Taipei 112, Taiwan; cyhsu@ntunhs.edu.tw

3 Master Program in Global Health and Development, College of Public Health, Taipei Medical University, 250 Wu-Hsing Street, Xinyi District, Taipei 110, Taiwan

4 School of Nutrition and Health Sciences, College of Nutrition, Taipei Medical University, 250 Wu-Hsing Street, Xinyi District, Taipei 110, Taiwan; rara.paramastri@gmail.com

5 Nutrition Research Center, Taipei Medical University Hospital, 252 Wu-Hsing Street, Xinyi District, Taipei 110, Taiwan

6 Department of Computer Science and Information Engineering, Tamkang University, 151 Yingzhuan Road, Tamsui District, New Taipei 251, Taiwan; billy72325@gmail.com

7 National Health Research Institutes, 35 Keyan Road, Zhunan Town, Miaoli County 350, Taiwan

8 Department of Health Technology, National Taipei University of Nursing and Health Sciences, 365 Ming-te Road, Beitou District, Taipei 112, Taiwan; amswurryjallow@gmail.com

* Correspondence: 8lukas@ntunhs.edu.tw (A.-L.K.); chenjui@tmu.edu.tw (J.C.-J.C.);

check for

updates

Citation: Kurniawan, A.-L.; Hsu, C.-Y.; Chao, J.C.-J.; Paramastri, R.; Lee, H.-A.; Jallow, A.-W. Association of Two Indices of Insulin Resistance Marker with Abnormal Liver Function Tests: A Cross-Sectional Population Study in Taiwanese Adults. Medicina 2022, 58, 4. https:// doi.org/10.3390/medicina58010004

Academic Editor: Manfredi Rizzo

Received: 29 October 2021

Accepted: 20 December 2021

Published: 21 December 2021

Publisher's Note: MDPI stays neutral with regard to jurisdictional claims in published maps and institutional affiliations.

Copyright: (c) 2021 by the authors. Licensee MDPI, Basel, Switzerland. This article is an open access article distributed under the terms and conditions of the Creative Commons Attribution (CC BY) license (https:// creativecommons.org/licenses/by/ $4.0 /)$.
Abstract: Background and objectives: Insulin resistance (IR) is frequently associated with chronic lowgrade inflammation and has an important role as a mediator in the development of liver disease. Thus, this study aimed to explore the relationship between two indexes of IR and abnormal liver function parameters. Materials and Methods: This cross-sectional study obtained data of 41,510 men and 92,357 women aged $\geq 30$ years from a private health screening institute in Taiwan. Two IR indexes namely triglyceride-glucose (TyG) index and triglycerides to high-density lipoprotein cholesterol (TG/HDLC) ratio were used to examine their relationship to predict abnormal liver function parameters (aspartate aminotransferase (AST), alanine aminotransferase (ALT), gamma-glutamyl transferase (GGT), and alkaline phosphatase (ALP)). Results: Positive trend was shown for the association of TyG index in the highest quintile (Q5) and risk of high AST (OR = 1.45, 95\% CI: 1.33-1.57), high ALT $(\mathrm{OR}=1.85,95 \%$ CI: 1.73-1.97), high GGT (OR $=2.04,95 \%$ CI: 1.93-2.15), and high ALP (OR = 1.13, 95\% CI: 1.07-1.19) compared with the median quintile (Q3) in the fully adjusted model. Similarly, participants in the Q5 of the TG/HDL-C ratio were associated with 1.38 (95\% CI: 1.27-1.49), 1.71 (95\% CI: 1.61-1.82), 1.75 (95\% CI: 1.66-1.84), and 1.21 (1.16-1.27) odds for having high AST, ALT, GGT, and ALP respectively. The AUC $(95 \% \mathrm{CI})$ value of the TyG index for predicting high AST, high ALT, and high GGT was 0.699 (0.692-0.705), 0.738 (0.734-0.742), and 0.752 (0.749-0.755), respectively. Meanwhile, the AUC (95\% CI) of the TG/HDL-C ratio for predicting high AST, high ALT, and high GGT was 0.680 (0.673-0.686), 0.738 (0.734-0.742), 0.734 (0.731-0.738), respectively. Conclusions: Our study supported that the TyG index and TG/HDL-C ratio may be useful as non-invasive methods to predict the existence of impaired liver function in the early stage.

Keywords: insulin resistance; liver function; triglyceride-glucose index; triglycerides to high-density lipoprotein cholesterol ratio 


\section{Introduction}

Abnormal liver function determined by high plasma concentrations of liver enzymes is associated with type 2 diabetes (T2D) [1,2]. Insulin resistance (IR) remains the most robust indicator or progenitor of T2D and plays a critical role in the pathogenesis of diabetesrelated comorbidities including cardiovascular disease and non-alcoholic fatty liver disease (NAFLD) [3]. The liver plays a key role in glucose metabolism by regulating various metabolic pathways such as glycolysis, glycogenesis, gluconeogenesis, and glycogenolysis [4]. Despite the leading-edge of liver disease diagnosis that has been primarily through biopsy or liver imaging, a non-invasive approach has been widely performed to assess liver abnormalities [5]. Alanine aminotransferase (ALT), aspartate aminotransferase (AST), gamma-glutamyl transferase (GGT), and alkaline phosphatase (ALP) are common major liver biomarkers used in clinical practice to assess impaired liver function [6]. A previous cross-sectional study has documented that NAFLD and liver biomarkers are significantly associated with three confirmed indices of hepatic IR [7]. Elevated IR is usually related to long-standing liver impairment and is a pathophysiological feature of hepatogenous insulin intolerance [8]. Researchers assumed that abnormal liver function augments hepatic IR to increase type 2 diabetes risk [9]. On the other hand, type 2 diabetes and IR lead to chronic hepatomegaly and immunological changes that enhance the abnormality of liver function [10]. However, it is not well known whether abnormal liver function leads to, originates from, or is simply related to IR and type 2 diabetes, as the underlying factors have not yet been elucidated [11,12].

A hyperinsulinemic-euglycemic clamp was recommended as the goal standard for quantifying IR. Since the clamp technique is costly and tedious, it is no longer durable for daily clinical practice [13]. Likewise, the homeostasis model assessment of insulin resistance (HOMA-IR) method, which calculates IR by integrating fasting glucose and insulin levels, is less invasive and tedious [14,15]. Although, the HOMA-IR indices are more widely used and beneficial in epidemiological and clinical studies for forecasting diabetes incidence in different groups. However, their application in clinical settings is minimal due to a lack of reference values for normal and abnormal insulin sensitivity [16].

Recently, the triglyceride-glucose (TyG) index and triglycerides to high-density lipoprotein cholesterol (TG/HDL-C) ratio have emerged as feasible tools for assessing IR in clinical therapy. The TyG index, defined as the product of fasting triglycerides and glucose levels, has been proposed as an ideal surrogate marker to evaluate IR $[17,18]$. The TyG index might represent an effective and simple tool to detect abnormal liver function when other procedures are unfitted [19]. Alternatively, the significance of the TG/HDL-C ratio in clinical practice has been investigated in many overwhelming studies. The procedure was considered simple and strongly recommended for the evaluation of insulin resistance $[18,20]$, atherogenic dyslipidemia [20], and metabolic syndrome [21]. Other studies have also compared the TyG index and TG/HDL-C ratio with IR sensitivity. It has been reported that the TyG index and TG/HDL-C ratio both have a strong correlation with IR [22,23]. Despite the fact that insulin sensitivity might be further associated with impaired liver function, we found few studies demonstrating a relationship between the two indices of IR and abnormal liver function. Early detection of abnormal liver function could be essential for public health interventions and, more importantly, a simple and ideal diagnostic tool that allows timely detection and treatment. The TyG index and TG/HDL-C ratio might be feasible tools to assess abnormal liver function in large population-based epidemiological studies, as both techniques are easy, non-invasive, and less tedious compared to the old diagnostic techniques. The performance of the newly developed techniques such as the TyG index and TG/HDL-C ratio may also surpass the performance of the old techniques in terms of their poor reliability and reproducibility. Therefore, it would be necessary to develop and evaluate the use of the two indices of insulin resistance for the assessment of abnormal liver function in clinical and epidemiological studies. Since the two indices are strongly associated with IR and IR precedes metabolic syndrome as well as abnormal liver 
function. Thus, the present study was designed to investigate the association between the two indices of IR and abnormal liver condition.

\section{Materials and Methods}

\subsection{Subjects and Study Design}

The study participants were individuals who visited the Mei Jau Health Management (MJHM) Institution in Taiwan for an annual health examination from 2001 to 2015. All participants attended a standardized medical screening program in four MJHM health clinics throughout Taiwan (Taipei, Taoyuan, Taichung, and Kaohsiung), completed a validated self-administered questionnaire, underwent a physical examination, and provided blood samples for laboratory tests. In the present study, we initially selected women and men who were 30 years or older ( $n=307,858$; women $n=233,776$, men $n=74,082)$. The exclusion criteria were: (1) had all types of cancer $(n=6080)$; (2) had hepatitis, cirrhosis, stroke, hyperthyroidism, and kidney disease $(n=41,464)$; and (3) had multiple entries (participants who had more than one annual health examination) $(n=126,447)$. A total of 41,510 men and 92,357 women $(n=133,867)$ met the inclusion criteria and were used for analysis. All participants provided informed consent for allowing their data to be processed, their identification was removed, and they remained anonymous throughout the study. The study protocols were approved by the Taipei Medical University Joint Institutional Review Board (TMU-JIRB N202010035).

\subsection{Clinical Measurements}

Anthropometry was obtained including weight and height (Nakamura KN-5000A, Tokyo, Japan), waist and hip circumference, percentage of body fat (Tanita TBF-410, Champaign, IL, USA), and blood pressure (BP) (Omron HEM-7201, Kyoto, Japan). Body mass index $(\mathrm{BMI})$ was calculated as weight $(\mathrm{kg}) /$ height square $(\mathrm{m})$ and classified as normal $\left(18.5 \mathrm{~kg} / \mathrm{m}^{2} \leq \mathrm{BMI}<24 \mathrm{~kg} / \mathrm{m}^{2}\right)$ or overweight to obese (BMI $\left.\geq 24 \mathrm{~kg} / \mathrm{m}^{2}\right)$ [24]. BP was measured twice at 10 min intervals after participants had been sitting for 5 min. Hypertension was defined as systolic/diastolic BP $\geq 140 / 90$ or taking antihypertensive drugs [25]. Blood samples were collected after at least $8 \mathrm{~h}$ of overnight fasting and analyzed for the liver function test (aspartate aminotransferase (AST), alanine aminotransferase (ALT), gamma-glutamyl transferase (GGT), and alkaline phosphatase (ALP)), fasting blood glucose (FBG), triglycerides (TG), total cholesterol (TC), low-density lipoprotein cholesterol (LDL-C), high-density lipoprotein cholesterol (HDL-C), uric acid, creatinine, estimated glomerular filtration rate (eGFR), C-reactive protein (CRP), neutrophils, and lymphocytes. All blood samples were determined using an automated analyzer (Toshiba C8000, Tokyo, Japan) and performed at MJHM central laboratory with a coefficient of variation of less than 3\%. The TyG index was calculated as described previously: TyG $=\mathrm{Ln}[\mathrm{TG}(\mathrm{mg} / \mathrm{dL}) \times$ FBG (mg/dL)/2] [17]. In addition, the TG/HDL ratio was calculated as TG (mg/dL)/HDLcholesterol $(\mathrm{mg} / \mathrm{dL})$.

Diabetes was determined as FBG $\geq 126 \mathrm{mg} / \mathrm{dL}$ or taking antihyperglycemic drugs [26]. Hyperuricemia was defined as uric acid $>420 \mu \mathrm{mol} / \mathrm{L}$ in men and $>360 \mu \mathrm{mol} / \mathrm{L}$ in women [27]. Reduced renal function was considered as eGFR $<60 \mathrm{~mL} / \mathrm{min} / 1.73 \mathrm{~m}^{2}$ calculated according to chronic kidney disease epidemiology (CKD-EPI) equation [28]. High inflammation was considered as CRP $\geq 28.6 \mathrm{nmol} / \mathrm{L}$ or neutrophil-to-lymphocyte ratio $(\mathrm{NLR}) \geq 3.0$ [29]. High AST, ALT, GGT, and ALP were defined as AST $>35 \mathrm{IU} / \mathrm{L}$, ALT > $40 \mathrm{IU} / \mathrm{L}, \mathrm{GGT}>30 \mathrm{IU} / \mathrm{L}$, and ALP > $120 \mathrm{IU} / \mathrm{L}$ respectively [30,31].

\subsection{Other Covariates}

Other variables collected from the self-reported questionnaire were age, marital status (single or married), educational level (below or above university level), annual income, physical activity or sports status, sleep time, sleep status, smoking status, alcohol consumption, and presence of cardiovascular disease. Physical activity status (intensity (light, moderate, heavy, intense) and duration (hours per week)) was categorized as 'active' if 
participants had at least moderate intensity with a minimum duration of $\geq 1$ to $2 \mathrm{~h}$ per week and 'inactive' if otherwise. Sleep status was categorized as 'insomnia' and 'sleep well' according to the previous study [32]. Cardiovascular status was defined as a history of cardiovascular disease (CVD) or taking CVD drugs. Food consumption was assessed using a standardized and validated semi-quantitative food frequency questionnaire (FFQ). Participants were asked how often and in what portions they consumed 22 food items in the past month (i.e., portions per day or week, from lowest to highest frequency). Three dietary patterns were identified using principal component analysis, and food items were retained in the pattern if the absolute cut-off value of a factor loading was $\geq 0.30$ (Supplementary Table S1). Dietary pattern scores were calculated for each pattern by summing up the frequency of food items weighted by their factor loadings [33].

\subsection{Statistical Analysis}

All statistical analyses were performed using STATA version 26 (StataCorp LP, College Station, TX, USA). Data were presented as number (percentage) for categorical variables and as mean \pm standard deviation (SD) for continuous variables. Differences between quintiles of the TyG index and TG/HDL-C ratio were assessed using the chi-square test for categorical variables and a general linear model for continuous variables. Binary robust logistic regression analysis was performed to calculate the odds ratio (OR) and 95\% confidence intervals (CI) for abnormal liver function in the different TyG and TG/HDL-C quintiles. The 3rd quintile (Q3 - the median quintile of the population) was used as the reference category because the cut-off point for the TyG index in previous studies [19,34] was between the Q3 range. Two adjustment models were applied: Model 1 was adjusted for age, gender, BMI, body fat, waist-to-hip circumference (WHR), marital status, education level, physical activity, annual income, smoking, alcohol consumption, sleeping status (condition and time), hypertension, diabetes, and CVD status. Model 2 was adjusted for all variables in model 1 plus hyperuricemia, reduced kidney function, high inflammation, TC levels, and LDL-C levels. Multivariable-adjusted logistic regression for abnormal liver function tests associated with the highest quintiles of TyG index and TG/HDL-C ratio, compared with median quintile was further estimated in subgroups analysis by gender, age group, BMI, hyperuricemia status, and high inflammatory status. Finally, receiver operating characteristic (ROC) curve analysis was performed to obtain the area under the curve (AUC) and to test the predictive power of the TyG index and TG/HDL-C ratio for abnormal liver function. The optimal cut-off point for the TyG index and TG/HDL-C ratio was determined using the value that represents the best specificity and sensitivity and referring to previous studies $[19,34]$. The ROC curve was plotted using SPSS version 23 (IBM Corp., IL, USA). A two-sided $p$-value $<0.05$ indicates statistical significance.

\section{Results}

\subsection{Characteristics of the Study Population}

Table 1 presents the characteristics of the study population according to quintiles of the TyG index and TG/HDL-C ratio. Among a total of 133,867 participants, the overall prevalence of high AST, ALT, GGT, and ALP levels was 5.8\% $(n=7712), 11.9 \%(n=15,891)$, $18.0 \%(n=24,091)$, and $21.4 \%(n=28,588)$, respectively. All the characteristics differed significantly $(p<0.05)$ across the quintiles of both the TyG index and the TG/HDL-C ratio, except for the Western-style dietary scores in the TyG index quartiles. As expected, the prevalence of abnormal liver function tests was significantly increased with increasing quintiles of the TyG index and TG/HDL-C ratio (Table 1). 
Table 1. Characteristics of the participants according to quintiles of TyG index and TG/HDL-C ratio.

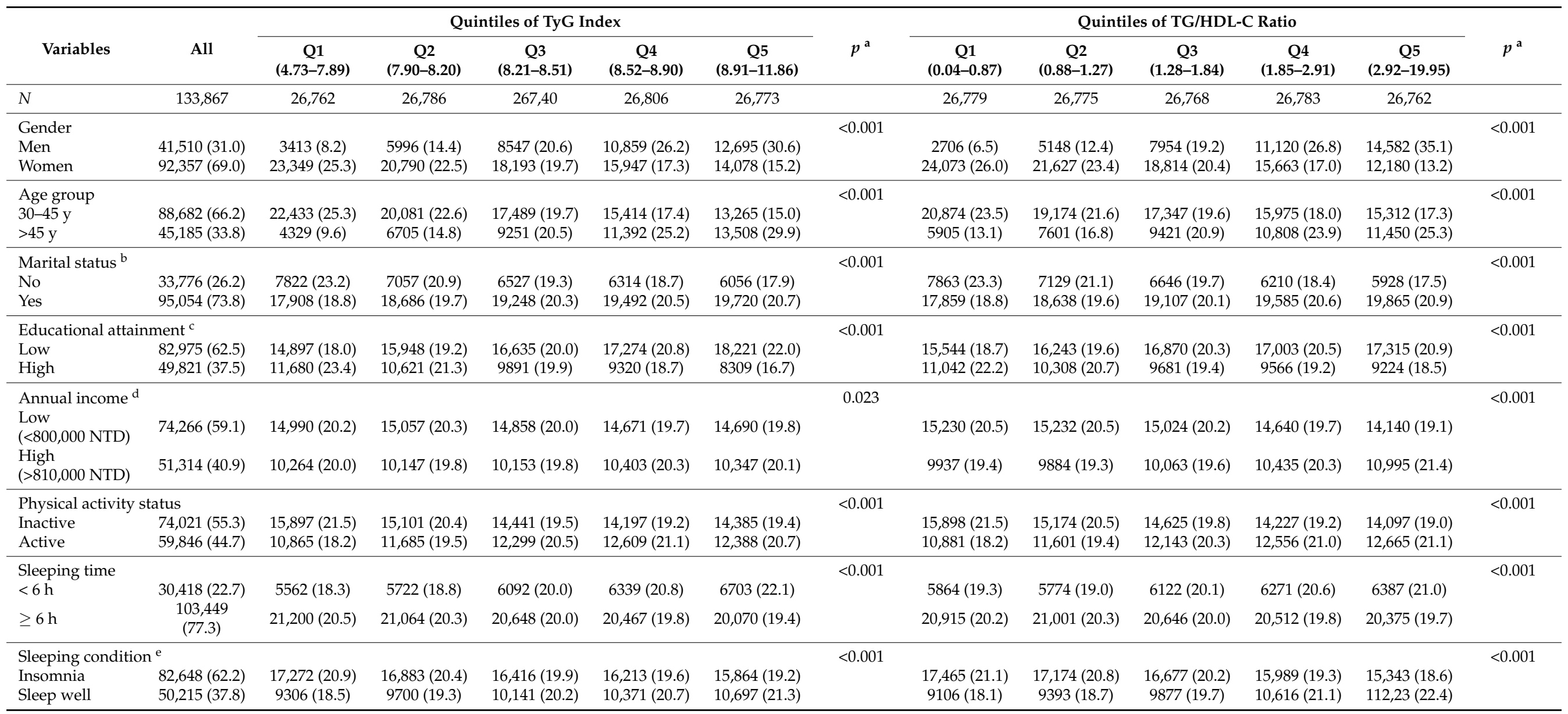


Table 1. Cont.

\begin{tabular}{|c|c|c|c|c|c|c|c|c|c|c|c|c|c|}
\hline \multirow[b]{2}{*}{ Variables } & \multirow[b]{2}{*}{ All } & \multicolumn{5}{|c|}{ Quintiles of TyG Index } & \multirow[b]{2}{*}{$p^{\mathrm{a}}$} & \multicolumn{5}{|c|}{ Quintiles of TG/HDL-C Ratio } & \multirow[b]{2}{*}{$p^{\mathrm{a}}$} \\
\hline & & $\begin{array}{c}\mathrm{Q1} \\
(4.73-7.89)\end{array}$ & $\begin{array}{c}\mathrm{Q} 2 \\
(7.90-8.20)\end{array}$ & $\begin{array}{c}\mathrm{Q3} \\
(8.21-8.51)\end{array}$ & $\begin{array}{c}\mathrm{Q} 4 \\
(8.52-8.90)\end{array}$ & $\begin{array}{c}\text { Q5 } \\
(8.91-11.86)\end{array}$ & & $\begin{array}{c}\mathrm{Q} 1 \\
(0.04-0.87)\end{array}$ & $\begin{array}{c}\mathrm{Q} 2 \\
(0.88-1.27)\end{array}$ & $\begin{array}{c}\text { Q3 } \\
(1.28-1.84)\end{array}$ & $\begin{array}{c}\mathrm{Q} 4 \\
(1.85-2.91)\end{array}$ & $\begin{array}{c}\text { Q5 } \\
(2.92-19.95)\end{array}$ & \\
\hline Smoker ${ }^{f}$ & $27,727(21.1)$ & $3854(13.9)$ & $4582(16.5)$ & $5324(19.2)$ & $6268(22.6)$ & $7699(27.8)$ & $<0.001$ & $3668(13.2)$ & $4212(15.2)$ & $5154(18.6)$ & $6282(22.7)$ & $8411(30.3)$ & $<0.001$ \\
\hline \multicolumn{14}{|c|}{ Presence of diseases } \\
\hline Hypertension & $19,476(14.6)$ & $1043(5.4)$ & $2040(10.5)$ & 3385 (17.4) & $5170(26.5)$ & $7838(40.2)$ & $<0.001$ & $1539(7.9)$ & 2469 (12.7) & $3687(18.9)$ & $5154(26.5)$ & $6627(34.0)$ & $<0.001$ \\
\hline Diabetes & $5824(4.4)$ & $121(2.1)$ & $213(3.6)$ & $379(6.5)$ & $884(15.2)$ & 4227 (72.6) & $<0.001$ & $276(4.7)$ & $455(7.8)$ & $872(15.0)$ & $1501(25.8)$ & $2720(46.7)$ & $<0.001$ \\
\hline Hyperuricemia & $31,232(23.3)$ & $2116(6.8)$ & $3607(11.6)$ & $5353(17.1)$ & $8256(26.4)$ & $11,900(38.1)$ & $<0.001$ & $2015(6.4)$ & $3558(11.4)$ & $5374(17.2)$ & $8215(26.3)$ & $12,070(38.7)$ & $<0.001$ \\
\hline $\begin{array}{l}\text { Reduced renal } \\
\text { function }\end{array}$ & $3642(2.7)$ & $182(5.0)$ & $376(10.3)$ & $597(16.4)$ & $955(26.2)$ & $1532(42.1)$ & $<0.001$ & $279(7.6)$ & $458(12.6)$ & $674(18.5)$ & $913(25.1)$ & $1318(36.2)$ & $<0.001$ \\
\hline $\begin{array}{l}\text { High } \\
\text { inflammation }\end{array}$ & $22,120(16.5)$ & $3170(14.3)$ & 3589 (16.2) & $4245(19.2)$ & $4941(22.3)$ & $6175(28.0)$ & $<0.001$ & $2979(13.5)$ & $3643(16.5)$ & $4384(19.8)$ & $5192(23.5)$ & $5922(26.7)$ & \\
\hline \multicolumn{14}{|c|}{ Liver function status } \\
\hline High AST & $7650(5.72)$ & $561(7.3)$ & $763(10.0)$ & $1163(15.2)$ & $1692(22.1)$ & $3471(45.4)$ & $<0.001$ & $641(8.4)$ & $814(10.6)$ & 1168 & 1795 & $3232(42.2)$ & $<0.001$ \\
\hline High ALT & $15,853(11.8)$ & $800(5.0)$ & $1342(8.5)$ & $2350(14.8)$ & 3948 (24.9) & $7413(46.8)$ & $<0.001$ & $863(5.4)$ & $1301(8.2)$ & $2276(14.4)$ & $4001(25.2)$ & $7412(46.8)$ & \\
\hline High GGT & $24,035(18.0)$ & $1212(5.0)$ & $2152(9.0)$ & $3570(14.9)$ & 6037 (25.1) & $11,064(46.0)$ & $<0.001$ & $1478(6.1)$ & $2249(9.4)$ & $3692(15.4)$ & $6076(25.3)$ & $10,540(43.8)$ & $<0.001$ \\
\hline High ALP & $28,568(21.3)$ & $3393(11.9)$ & 5056 (17.7) & $6080(21.3)$ & $6748(23.6)$ & $7291(25.5)$ & $<0.001$ & $3564(12.5)$ & 5037 (17.6) & $5837(20.4)$ & $6652(23.3)$ & 7478 (26.2) & $<0.001$ \\
\hline $\begin{array}{l}\text { Vege-seafood } \\
\text { style }\end{array}$ & $8.5 \pm 1.9$ & $8.5+2.0$ & $8.4 \pm 1.9$ & $8.5 \pm 1.9$ & $8.5 \pm 1.9$ & $8.5 \pm 2.0$ & $<0.001$ & $8.5 \pm 1.9$ & $8.5 \pm 1.9$ & $8.5 \pm 1.9$ & $8.5 \pm 1.9$ & $8.5 \pm 1.9$ & 0.002 \\
\hline $\begin{array}{l}\text { American } \\
\text { breakfast style }\end{array}$ & $5.5 \pm 1.4$ & $5.5 \pm 1.4$ & $5.5 \pm 1.4$ & $5.5 \pm 1.4$ & $5.5 \pm 1.4$ & $5.4 \pm 1.4$ & $<0.001$ & $5.5 \pm 1.4$ & $5.5 \pm 1.4$ & $5.5 \pm 1.4$ & $5.5 \pm 1.4$ & $5.4 \pm 1.4$ & $<0.001$ \\
\hline \multicolumn{14}{|l|}{ Anthropometry } \\
\hline BMI, $\mathrm{kg} / \mathrm{m}^{2}$ & $23.0 \pm 3.5$ & $20.8 \pm 2.5$ & $21.7 \pm 2.9$ & $22.8 \pm 3.2$ & $24.1 \pm 3.4$ & $25.4 \pm 3.5$ & $<0.001$ & $20.7 \pm 2.5$ & $21.7 \pm 2.9$ & $22.9 \pm 3.2$ & $24.1 \pm 3.4$ & $25.4 \pm 3.4$ & $<0.001$ \\
\hline Body fat, $\%$ & $27.8 \pm 7.1$ & $25.1 \pm 5.5$ & $26.3 \pm 6.3$ & $27.7 \pm 7.0$ & $29.2 \pm 7.3$ & $30.8 \pm 7.5$ & $<0.001$ & $25.2 \pm 5.6$ & $26.7 \pm 6.4$ & $28.0 \pm 7.1$ & $29.2 \pm 7.5$ & $30.0 \pm 7.4$ & $<0.001$ \\
\hline WHR & $0.8 \pm 0.1$ & $0.7 \pm 0.1$ & $0.8 \pm 0.1$ & $0.8 \pm 0.1$ & $0.8 \pm 0.1$ & $0.9 \pm 0.1$ & $<0.001$ & $0.7 \pm 0.1$ & $0.8 \pm 0.1$ & $0.8 \pm 0.1$ & $0.8 \pm 0.1$ & $0.9 \pm 0.1$ & $<0.001$ \\
\hline
\end{tabular}


Table 1. Cont.

\begin{tabular}{|c|c|c|c|c|c|c|c|c|c|c|c|c|c|}
\hline \multirow[b]{2}{*}{ Variables } & \multirow[b]{2}{*}{ All } & \multicolumn{5}{|c|}{ Quintiles of TyG Index } & \multirow[b]{2}{*}{$p^{\mathrm{a}}$} & \multicolumn{5}{|c|}{ Quintiles of TG/HDL-C Ratio } & \multirow[b]{2}{*}{$p^{\mathrm{a}}$} \\
\hline & & $\begin{array}{c}\text { Q1 } \\
(4.73-7.89)\end{array}$ & $\begin{array}{c}\mathrm{Q} 2 \\
(7.90-8.20)\end{array}$ & $\begin{array}{c}\mathrm{Q} 3 \\
(8.21-8.51)\end{array}$ & $\begin{array}{c}\mathrm{Q} 4 \\
(8.52-8.90)\end{array}$ & $\begin{array}{c}\text { Q5 } \\
(8.91-11.86)\end{array}$ & & $\begin{array}{c}\mathrm{Q1} \\
(0.04-0.87)\end{array}$ & $\begin{array}{c}\mathrm{Q} 2 \\
(0.88-1.27)\end{array}$ & $\begin{array}{c}\mathrm{Q3} \\
(1.28-1.84)\end{array}$ & $\begin{array}{c}\mathrm{Q} 4 \\
(1.85-2.91)\end{array}$ & $\begin{array}{c}\text { Q5 } \\
(2.92-19.95)\end{array}$ & \\
\hline \multicolumn{14}{|c|}{ Blood biochemistry } \\
\hline $\mathrm{FBG}, \mathrm{mg} / \mathrm{dL}$ & $99.4 \pm 19.6$ & $91.6 \pm 6.9$ & $94.6 \pm 7.4$ & $97.1 \pm 8.5$ & $100.1 \pm 11.0$ & $113.4 \pm 36.4$ & $<0.001$ & $93.7 \pm 9.9$ & $95.8 \pm 12.3$ & $98.5 \pm 16.3$ & $101.7 \pm 20.4$ & $107.2 \pm 29.4$ & $<0.001$ \\
\hline $\mathrm{TG}, \mathrm{mg} / \mathrm{dL}$ & $105.8 \pm 66.1$ & $47.3 \pm 8.4$ & $67.5 \pm 7.4$ & $88.4 \pm 10.1$ & $120.7 \pm 16.9$ & $205.2 \pm 77.6$ & $<0.001$ & $49.5 \pm 11.1$ & $68.7 \pm 13.0$ & $88.8 \pm 17.1$ & $119.3 \pm 24.0$ & $202.9 \pm 79.0$ & $<0.001$ \\
\hline $\mathrm{TC}, \mathrm{mg} / \mathrm{dL}$ & $194.8 \pm 35.2$ & $177.6 \pm 30.1$ & $186.2 \pm 31.3$ & $193.9 \pm 32.1$ & $202.9 \pm 33.8$ & $213.5 \pm 36.7$ & $<0.001$ & $186.4 \pm 31.9$ & $188.0 \pm 32.9$ & $192.7 \pm 34.2$ & $200.0 \pm 35.4$ & $207.2 \pm 36.8$ & $<0.001$ \\
\hline LDL-C, mg/dL & $115.2 \pm 31.7$ & $99.5 \pm 26.2$ & $109.0 \pm 28.3$ & $117.1 \pm 29.6$ & $124.9 \pm 31.4$ & $125.5 \pm 34.5$ & $<0.001$ & $100.7 \pm 27.4$ & $109.5 \pm 28.8$ & $117.2 \pm 30.3$ & $124.9 \pm 31.6$ & $123.7 \pm 33.6$ & $<0.001$ \\
\hline HDL-C, mg/dL & $59.1 \pm 15.3$ & $68.6 \pm 14.9$ & $63.9 \pm 14.4$ & $59.6 \pm 14.0$ & $54.8 \pm 13.0$ & $48.6 \pm 11.3$ & $<0.001$ & $75.6 \pm 13.9$ & $65.0 \pm 11.4$ & $58.3 \pm 10.4$ & $52.1 \pm 9.3$ & $44.4 \pm 8.3$ & $<0.001$ \\
\hline \multicolumn{14}{|c|}{ Insulin resistance indexes } \\
\hline $\begin{array}{l}\text { TyG index } \\
\text { TG/HDL-C } \\
\text { ratio }\end{array}$ & $2.0 \pm 1.7$ & $0.7 \pm 0.2$ & $1.1 \pm 0.3$ & $1.6 \pm 0.4$ & $2.3 \pm 0.7$ & $4.5 \pm 2.3$ & $<0.001$ & $0.7 \pm 0.1$ & $1.1 \pm 0.1$ & $1.5 \pm 0.2$ & $2.3 \pm 0.3$ & $4.7 \pm 1.8$ & $<0.001$ \\
\hline
\end{tabular}

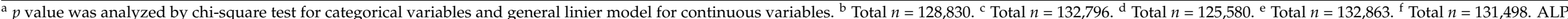

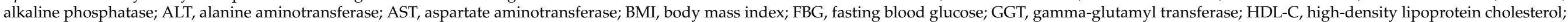
LDL-C, low-density lipoprotein cholesterol; TC, total cholesterol; TG, triglyceride; TyG, triglyceride-glucose index; WHR, waist to hip ratio. 


\subsection{Association between TyG Index and TG/HDL-C Ratio with Abnormal Liver Function}

Table 2 shows the adjusted ORs for the association between quintiles of the TyG index and abnormal liver function tests. A fully adjusted model showed that participants in the highest quintiles (Q5) of TyG index was positively associated with increased risk of high AST (OR $=1.45,95 \%$ CI: 1.33-1.57), high ALT (OR = 1.85, 95\% CI: 1.73-1.97), high GGT $(\mathrm{RO}=2.04,95 \% \mathrm{CI}: 1.93-2.15)$, and high ALP (OR $=1.13,95 \% \mathrm{CI}: 1.07-1.19)$ compared to the median quintile (Q3). There was a similar trend of a positive association in the quintile 4 (Q4) of the TyG index for predicting abnormal liver function tests, except for high AST $(\mathrm{OR}=1.07,95 \% \mathrm{CI}: 0.98-1.16, p=0.125)$. The AUC $(95 \% \mathrm{CI})$ value of the TyG index for predicting high AST, high ALT, and high GGT was 0.699 (0.692-0.705), 0.738 (0.734-0.742), and $0.752(0.749-0.755)$, respectively. Using the optimal cut-off point of 8.50, the sensitivity and specificity for predicting high AST, high ALT, and high GGT were $67.8 \%$ and $61.7 \%$, $72.0 \%$ and $64.2 \%$, and $71.6 \%$ and $66.8 \%$, respectively (Figure 1 ).

Table 2. Multivariable adjusted logistic regression for abnormal liver function tests in different quintiles of TyG index and TG/HDL-C ratio.

\begin{tabular}{|c|c|c|c|c|c|c|c|c|}
\hline & \multicolumn{2}{|c|}{ High AST } & \multicolumn{2}{|c|}{ High ALT } & \multicolumn{2}{|c|}{ High GGT } & \multicolumn{2}{|c|}{ High ALP } \\
\hline & Model 1 & Model 2 & Model 1 & Model 2 & Model 1 & Model 2 & Model 1 & Model 2 \\
\hline \multicolumn{9}{|c|}{ TyG index } \\
\hline Q1 & $\begin{array}{c}0.83 \\
(0.74-0.93) * *\end{array}$ & $\begin{array}{c}0.86 \\
(0.77-0.97) *\end{array}$ & $\begin{array}{c}0.65 \\
(0.59-0.71) * *\end{array}$ & $\begin{array}{c}0.69 \\
(0.63-0.75) * *\end{array}$ & $\begin{array}{c}0.56 \\
(0.52-0.61)\end{array}$ & $\begin{array}{c}0.61 \\
(0.56-0.65) * *\end{array}$ & $\begin{array}{c}0.55 \\
(0.52-0.58) * *\end{array}$ & $\begin{array}{c}0.56 \\
(0.53-0.59) * *\end{array}$ \\
\hline Q2 & $\begin{array}{c}0.85 \\
(0.77-0.94) * *\end{array}$ & $\begin{array}{c}0.87 \\
(0.78-0.96) * *\end{array}$ & $\begin{array}{c}0.76 \\
(0.71-0.82) * *\end{array}$ & $\begin{array}{c}0.79 \\
(0.73-0.85) \text { ** }\end{array}$ & $\begin{array}{c}0.76 \\
(0.72-0.81) * *\end{array}$ & $\begin{array}{c}0.79 \\
(0.75-0.84) * *\end{array}$ & $\begin{array}{c}0.83 \\
(0.79-0.86) * *\end{array}$ & $\begin{array}{c}0.83 \\
(0.79-0.87) * *\end{array}$ \\
\hline Q3 & 1.00 & 1.00 & 1.00 & 1.00 & 1.00 & 1.00 & 1.00 & 1.00 \\
\hline Q4 & $\begin{array}{c}1.13 \\
(1.04-1.23) * *\end{array}$ & $\begin{array}{c}1.07 \\
(0.98-1.16)\end{array}$ & $\begin{array}{c}1.32 \\
(1.24-1.41)^{* *}\end{array}$ & $\begin{array}{c}1.25 \\
(1.17-1.33) * *\end{array}$ & $\begin{array}{c}1.47 \\
(1.40-1.54)^{* *}\end{array}$ & $\begin{array}{c}1.35 \\
(1.29-1.43) * *\end{array}$ & $\begin{array}{c}1.10 \\
(1.05-1.15)^{* *}\end{array}$ & $\begin{array}{c}1.07 \\
(1.02-1.11)^{* *}\end{array}$ \\
\hline Q5 & $\begin{array}{c}1.79 \\
(1.66-1.94) * *\end{array}$ & $\begin{array}{c}1.45 \\
(1.33-1.57) * *\end{array}$ & $\begin{array}{c}2.18 \\
(2.05-2.31) * *\end{array}$ & $\begin{array}{c}1.85 \\
(1.73-1.97) * *\end{array}$ & $\begin{array}{c}2.71 \\
(2.58-2.85) * *\end{array}$ & $\begin{array}{c}2.04 \\
(1.93-2.15) * *\end{array}$ & $\begin{array}{c}1.19 \\
(1.14-1.25)^{* *}\end{array}$ & $\begin{array}{c}1.13 \\
(1.07-1.19)\end{array}$ \\
\hline \multicolumn{9}{|c|}{ TG/HDL-C ratio } \\
\hline Q1 & $\begin{array}{c}0.98 \\
(0.88-1.09)\end{array}$ & $\begin{array}{c}0.91 \\
(0.81-1.01)\end{array}$ & $\begin{array}{c}0.82 \\
(0.75-0.90) * *\end{array}$ & $\begin{array}{c}0.78 \\
(0.71-0.85) * *\end{array}$ & $\begin{array}{c}0.72 \\
(0.67-0.77) * *\end{array}$ & $\begin{array}{c}0.61 \\
(0.57-0.66)\end{array}$ & $\begin{array}{c}0.59 \\
(0.56-0.62)\end{array}$ & $\begin{array}{c}0.60 \\
(0.57-0.64)^{* *}\end{array}$ \\
\hline Q2 & $\begin{array}{c}0.91 \\
(0.82-1.00)\end{array}$ & $\begin{array}{c}0.90 \\
(0.81-0.99)\end{array}$ & $\begin{array}{c}0.81 \\
(0.75-0.87)\end{array}$ & $\begin{array}{c}0.80 \\
(0.74-0.87) * *\end{array}$ & $\begin{array}{c}0.81 \\
(0.77-0.87)\end{array}$ & $\begin{array}{c}0.79 \\
(0.74-0.84) * *\end{array}$ & $\begin{array}{c}0.86 \\
(0.82-0.90)\end{array}$ & $\begin{array}{c}0.87 \\
(0.83-0.91)^{* *}\end{array}$ \\
\hline Q3 & 1.00 & 1.00 & 1.00 & 1.00 & 1.00 & 1.00 & 1.00 & 1.00 \\
\hline Q4 & $\begin{array}{c}1.14 \\
(1.05-1.23) * *\end{array}$ & $\begin{array}{c}1.10 \\
(1.01-1.19) *\end{array}$ & $\begin{array}{c}1.30 \\
(1.22-1.38)^{* *}\end{array}$ & $\begin{array}{c}1.25 \\
(1.18-1.33)^{* *}\end{array}$ & $\begin{array}{c}1.37 \\
(1.30-1.44) * *\end{array}$ & $\begin{array}{c}1.32 \\
(1.25-1.39) * *\end{array}$ & $\begin{array}{c}1.15 \\
(1.10-1.20) * *\end{array}$ & $\begin{array}{c}1.11 \\
(1.06-1.16)\end{array}$ \\
\hline Q5 & $\begin{array}{c}1.66 \\
(1.53-1.79)^{* *}\end{array}$ & $\begin{array}{c}1.38 \\
(1.27-1.49) * *\end{array}$ & $\begin{array}{c}2.02 \\
(1.90-2.14) * *\end{array}$ & $\begin{array}{c}1.71 \\
(1.61-1.82) * *\end{array}$ & $\begin{array}{c}2.23 \\
(2.12-2.34) * *\end{array}$ & $\begin{array}{c}1.75 \\
(1.66-1.84)^{* *}\end{array}$ & $\begin{array}{c}1.34 \\
(1.28-1.41)^{* *}\end{array}$ & $\begin{array}{c}1.21 \\
(1.16-1.27) * *\end{array}$ \\
\hline
\end{tabular}

Data are expressed as beta $(\beta)$ and $95 \%$ confidence intervals (CIs) in the parenthesis. Model 1: adjusted by age and gender, BMI, body fat, WHR, marital status, education level, physical activity status, income status, smoking, alcohol drinking, sleeping status (condition and time), hypertension, diabetes, and cardiovascular disease status. Model 2: adjusted by model $1+$ hyperuricemia, reduced kidney function, high inflammation, T-Cholesterol, LDL-C levels, and all type of dietary pattern scores. ${ }^{*} p<0.05,{ }^{* *} p<0.01$ for comparison of Q1, Q2, Q4, and Q5 to Q3.

Similar to the TyG index, a positive association towards a higher risk of abnormal liver function tests was observed as quintiles of the TG/HDL-C ratio. However, the TG/HDL-C ratio showed lower ORs associated with abnormal liver function tests of AST, ALT, and GGT than the TyG index. A fully adjusted model revealed that participants in the Q5 of the TG/HDL-C ratio were associated with 1.38 (95\% CI: 1.27-1.49), 1.71 (95\% CI: 1.61-1.82), 1.75 (95\% CI: 1.66-1.84), and 1.21 (1.16-1.27) odds for having high AST, ALT, GGT, and ALP, respectively (Table 2). Using the ROC curve, the optimal cut-off point for the TG/HDL-C ratio was 1.78 , yielding sensitivity and specificity of $66.9 \%$ and $60.1 \%$ for predicting high AST, $66.9 \%$ and $60.1 \%$ for predicting high ALT, and $70.7 \%$ and $64.8 \%$ for predicting high GGT (Figure 1). The AUC (95\% CI) of TG/HDL-C ratio for predicting high AST, high ALT, and high GGT was 0.680 (0.673-0.686), 0.738 (0.734-0.742), 0.734 (0.731-0.738), respectively. In contrast, the AUC value of both indices for predicting high ALP was relatively small ( 0.588 for TyG index and 0.590 for TG/HDL-C ratio), thus it generated lower sensitivity and specificity (TyG sensitivity and specificity: $49.6 \%$ and $61.9 \%$, respectively, and TG/HDL-C 
ratio sensitivity and specificity: $51.1 \%$ and $61.1 \%$ ). Moreover, compared with individual fasting blood glucose, triglyceride, and HDL-C levels, the AUC value of both TyG index and TG/HDL-C ratio was higher (Supplementary Table S2). Linear prediction of TyG index and TG/HDL-C ratio with serum liver function also showed a positive association (Supplementary Table S3, Supplementary Figures S1 and S2).

A

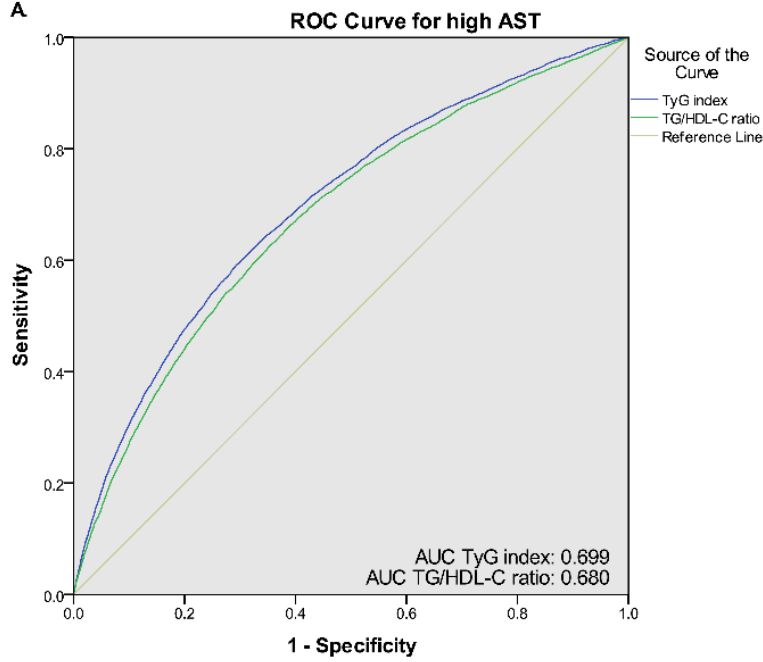

C.

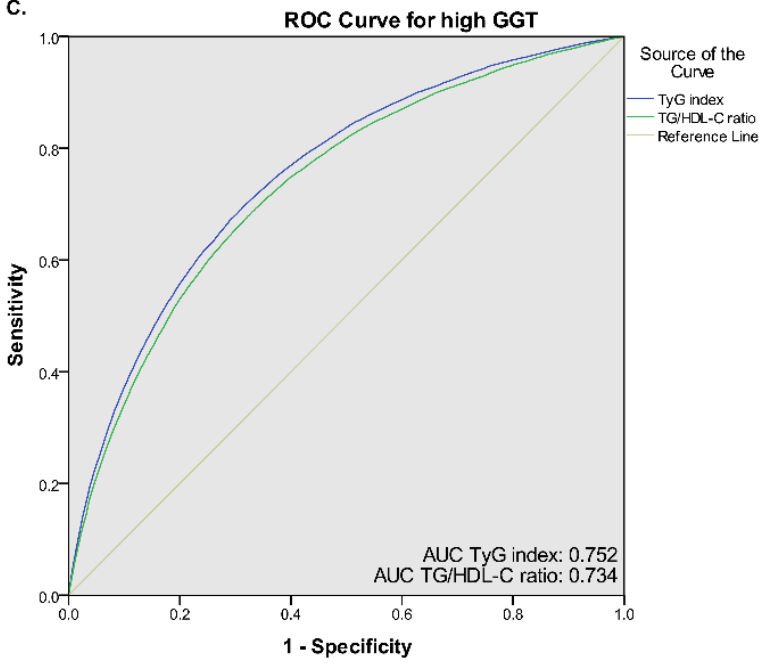

B.

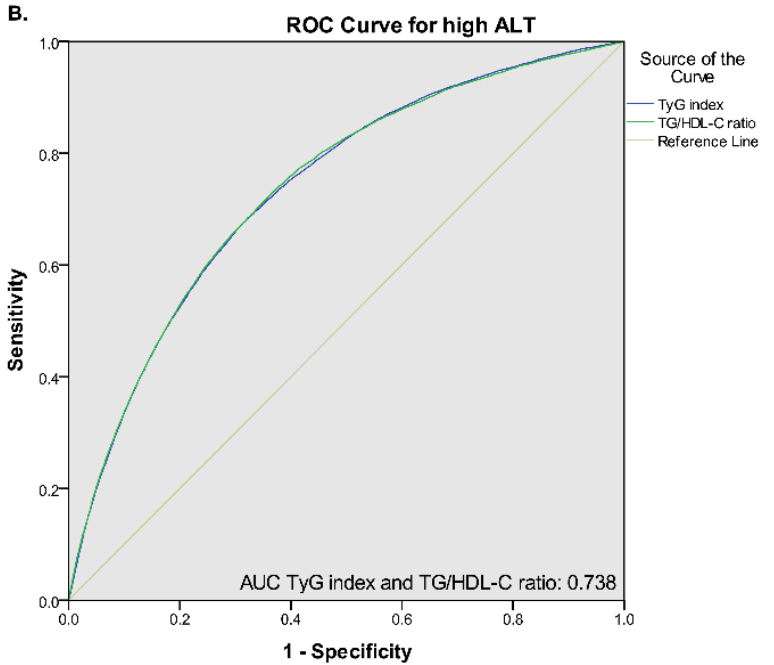

D.

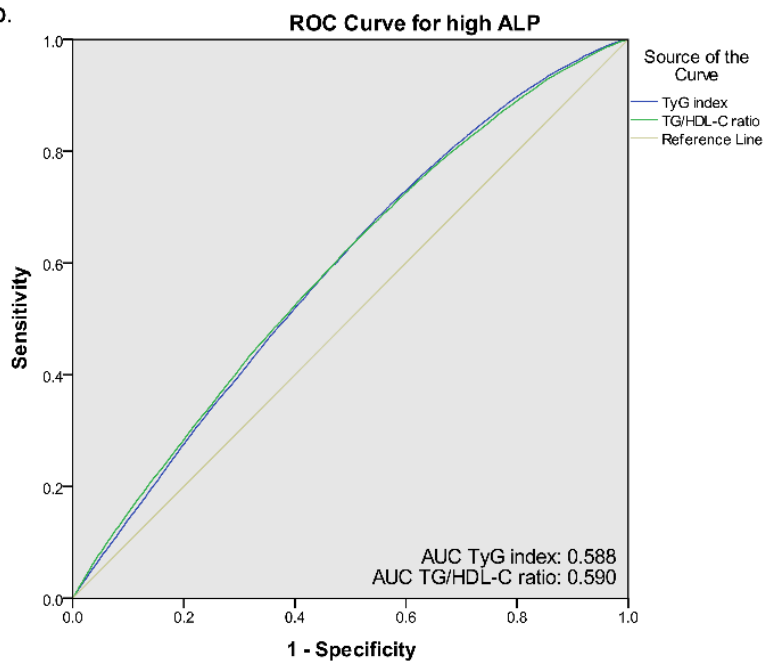

Figure 1. Receiver operative characteristic (ROC) curves of the TyG index and TG/HDL-C ratio for (A) high AST, (B) high ALT, (C) high GGT, and (D) high ALP.

\subsection{Subgroup Analysis According to TyG Index and TG/HDL-C Ratio}

We further divided the population into various subgroups and compared the predictive power of the TyG index and TG/HDL-C ratio. Subgroup analysis showed that the association of the TyG index and TG/HDL-C ratio for each abnormal liver function parameter remained robust in the highest quintile (Q5) of each subgroup studied compared with the median quintile (Q3) (Figures 2 and 3). However, the adjusted ORs for high ALP in hyperuricemic subjects were insignificant in Q5 of the TyG index $(\mathrm{OR}=1.05,95 \% \mathrm{CI}$ : $0.96-1.14, p=0.809$ ). The results of subgroup analysis in other quintiles were shown in Supplementary Table S4. 
A.

TyG index for high AST

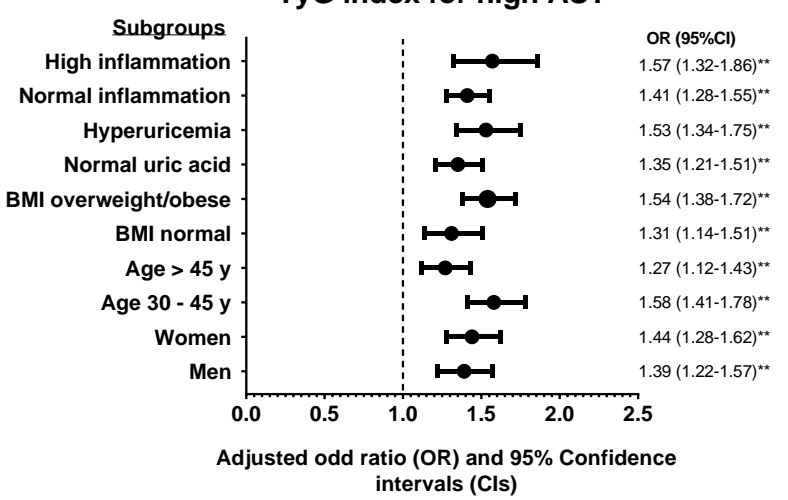

c.

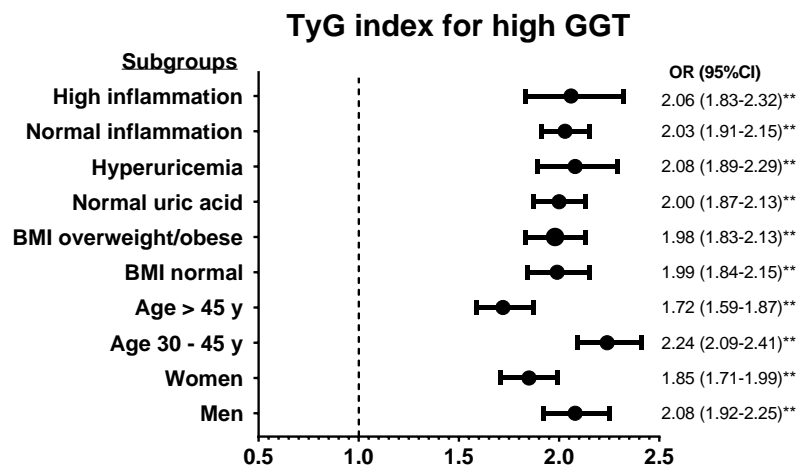

Adjusted odd ratio (OR) and 95\% Confidence intervals (Cls)

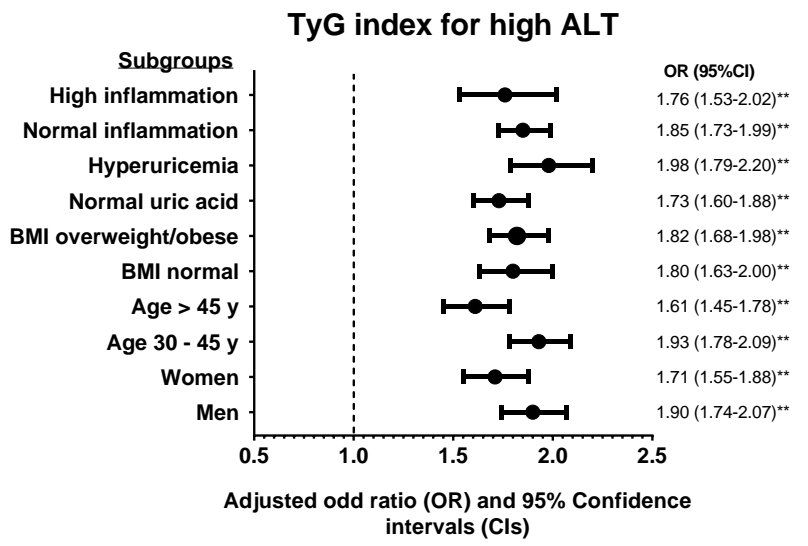

D.

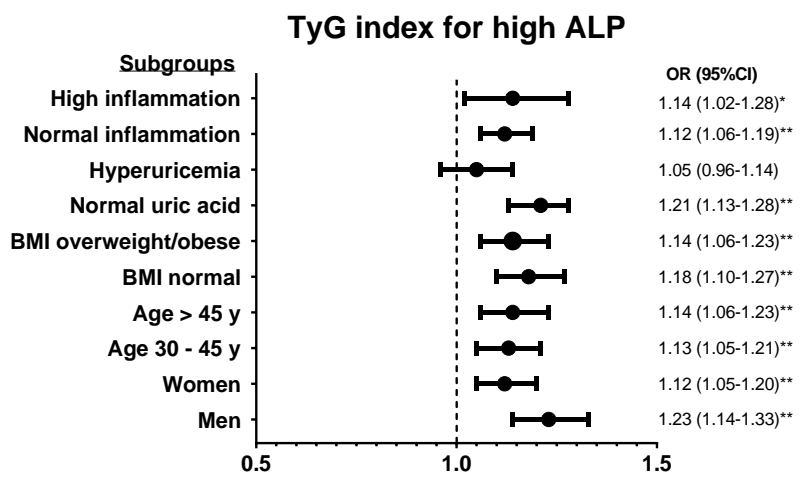

Adjusted odd ratio (OR) and $95 \%$ Confidence intervals (Cls)

Figure 2. Subgroup analysis of the association between TyG index in quintile 5 (Q4) with (A) high AST, (B) high ALT, (C) high GGT, and (D) high ALP. Quintile 3 (Q3) was used for the reference. The odds ratio (OR) was adjusted with model 2 except for stratified variables in each subgroup. ${ }^{*} p<0.05$, ** $p<0.01$ for comparison of Q5 to Q3.

A.

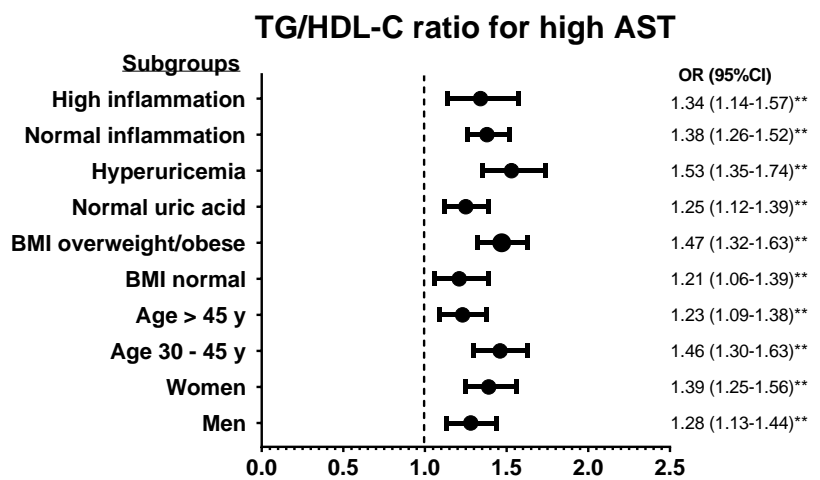

Adjusted odd ratio (OR) and $95 \%$ Confidence intervals (Cls)

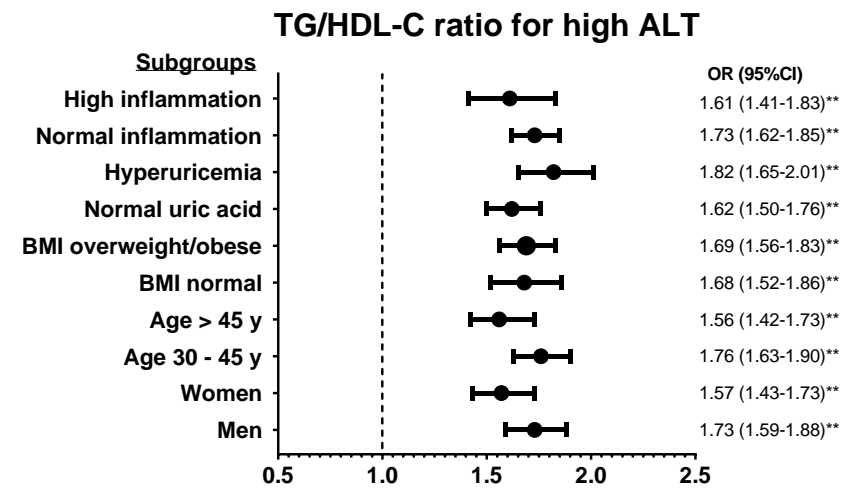

Adjusted odd ratio (OR) and $95 \%$ Confidence intervals (Cls)

Figure 3. Cont. 
c.

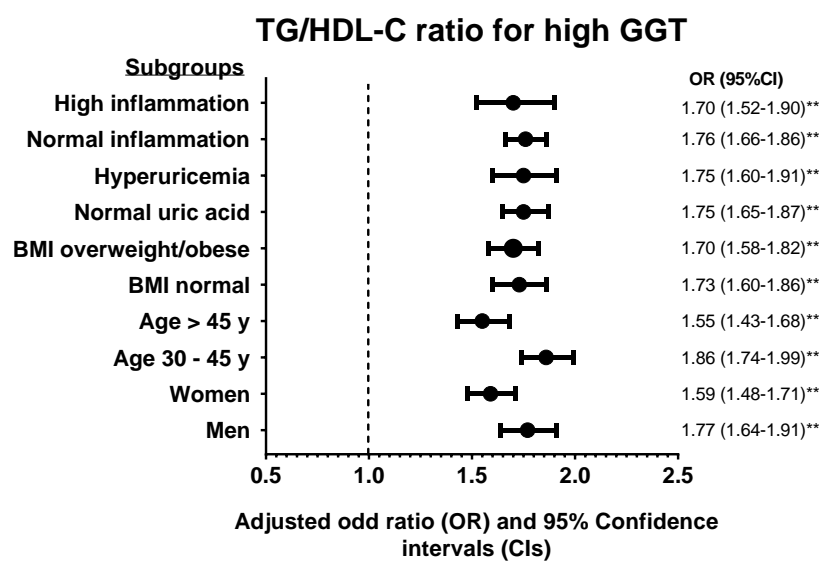

D.

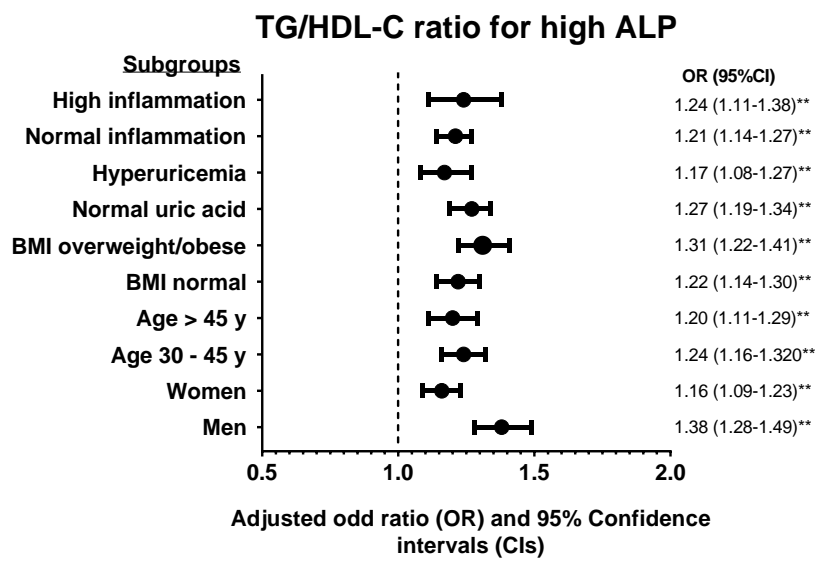

Figure 3. Subgroup analysis of the association between TG/HDL-C ratio in quintile 5 (Q4) with (A) high AST, (B) high ALT, (C) high GGT, and (D) high ALP. Quintile 3 (Q3) was used for the reference. The odds ratio (OR) was adjusted with model 2 except for stratified variables in each subgroup. ${ }^{* *} p<$ 0.01 for comparison of Q5 to Q3.

\section{Discussion}

Our data indicate that relatively new parameters, including the TyG index and the TG/HDL-C ratio as a surrogate of insulin resistance, might play a role in detecting abnormal liver function. We also demonstrated that a higher TyG index and TG/HDL-C ratio were positively associated with a higher risk of abnormal liver function after adjusting for potential confounders. We also analyzed the sensitivity and specificity of these two markers. Thus, we observed a similar result for the TyG index and the TG/HDL-C ratio in terms of detecting abnormal liver function.

Liver function is known to be related to insulin resistance and metabolic syndromes associated with elevated insulin, triglyceride, and glucose index [35]. A previous prospective cohort study has shown the potential role of the TyG index in identifying non-alcoholic liver function disease (NAFLD) [34]. In the present study, a higher TyG index indicated a higher risk of liver abnormalities. Similar to a previous cross-sectional study conducted on 10,761 Chinese over 20 years of age, the number of NAFLD was significantly increased with the increasing levels of TyG $(\mathrm{OR}=6.3,95 \% \mathrm{CI}: 5.3-7.5, p$ for trend < 0.0001) [19]. Furthermore, in a survey of 6445 Chinese adults, which covered urban and rural areas between 2011 and 2013, a significant association was found between more severe insulin resistance, as indicated by higher TyG index, and a higher risk of impaired liver function in a fully adjusted model (OR $=2.04,95 \%$ CI: 1.93-2.17, $p<0.0001)$ [15]. In our study, a higher ALT was observed in a group with higher TyG levels, which is consistent with a prior study that found an increase in ALT by 1.22 (95\% CI: 1.21-1.24) IU for a one-unit increment of TyG [15].

Our study also remarked that the TyG index with AUC values of 0.699 (AST), 0.738 (ALT), and 0.752 (GGT) could be an effective biomarker to identify impaired liver function. A high predictive value of the TyG index was also observed in a cross-sectional study of 4784 adult participants to identify NAFLD and liver fibrosis (AUC of 0.761) [36]. Similarly, a previous study also found a high predictive value of TyG (AUC $=0.782,95 \%$ CI: 0.77-0.79, $p<0.0001$ ) with a sensitivity of $72.2 \%$ and specificity of $70.5 \%$ [19]. This finding is expected since the TyG index, generated from TG and FBG, takes into account the two main metabolic variables affected in fatty liver and is closely coincides with insulin resistance, the main pathogenesis of NAFLD [19]. Importantly, in the SAM study, TyG was found to have a better correlation with altered hepatic insulin due to its strong association with hepatic fat distribution [37]. NAFLD is closely related to obesity and metabolic syndrome and is characterized by an abnormal accumulation of triglycerides in the liver, which contributes to hepatic insulin resistance. Hepatic insulin resistance leads to excessive production of 
FBG and VLDL, which contain abundant serum TG [38]. In particular, our findings revealed that participants in the highest quintile (Q5) of the TyG index had substantially higher BMI, body fat percentage, FBG, TC, TG, and LDL-C. Thus, according to these observations, it is reasonable to use the TyG index as an efficient diagnostic method to detect abnormal liver function [19].

Furthermore, our study demonstrated the potential role of the TG/HDL-C ratio in predicting impaired liver function. Interestingly, the TG/HDL-C ratio showed a similar trend to the TyG index, although the odds were relatively lower. In a previous cohort study conducted between May 1994 to December 2003 in 9039 Japanese adults, a strong association was observed between the TG/HDL-C ratio and an increased incidence of fatty liver disease $(\mathrm{OR}=1.55,95 \% \mathrm{CI}$ : $1.35-1.77, p<0.0001$ for men and $\mathrm{OR}=2.72,95 \%$ CI: $1.88-3.95, p<0.0001$ for women) [39]. Consistently, a previous study involving 18,061 Chinese adults who underwent a health checkup between May 2013 and June 2014 also indicated the strong association between the TG/HDL-C ratio and liver biomarkers, which $\mathrm{OR}$ and prevalence of abnormal liver function progressively increased across the quartile of the TG/HDL-C ratio [40].

We further examined the sensitivity and specificity of the TG/HDL-C ratio in detecting abnormal liver function by investigating the AUC. Our recent study demonstrated a relatively high AUC for predicting high AST, high ALT, and high GGT of 0.680 (0.673$0.686), 0.738(0.734-0.742)$, and $0.734(0.731-0.738)$, respectively. In accordance with the results of a prior retrospective cohort study among non-obese Chinese, TG/HDL-C ratio independently indicated abnormal liver function with AUC of 0.70 (0.68-0.72) in men and $0.72(0.70-0.75)$ in women [41]. Compared with other lipid parameters and markers of liver injury, the AUC of the TG/HDL-C ratio in a study of adult NAFLD patients was 0.79 for men and 0.85 for women [40]. Although the mechanism underlying the association between TG/HDL-C and abnormal liver function has not been fully elucidated, insulin resistance is a possible mediator. TG/HDL-C has been found to be essential for insulin sensitivity and cardiovascular risk assessment $[42,43]$. The increased TG/HDL$C$ ratio also indicates the presence of a small dense LDL cholesterol subclass (sdLDL), which is atherogenic lipoprotein, and plays a crucial role in insulin resistance and several chronic metabolic disorders $[44,45]$. Insulin resistance, therefore, facilitates liver injury by stimulating adiposity and lipolysis of TG in adipose tissue and the liver $[36,45]$. In addition, adiponectin may provide another link between TG/HDL-C and impaired liver function [46]. Prior investigations have shown that adiponectin elevates serum HDL-C and conversely decreases serum TG. Moreover, reduced adiponectin levels could lead to a higher TG/HDL-C ratio [19]. Further studies are needed to clarify whether adiponectin contributes to the association between TG/HDL-C and abnormal liver functions.

The strength of our study is the large sample size, comprehensive analysis, and subgroup analysis to determine which group generates better results. However, some limitations should be noted. First, our study is cross-sectional, therefore, we cannot establish the causal effect inference. Second, we did not directly measure insulin concentration. Moreover, imaging data and liver biopsy to confirm the abnormality of liver function were not available in the present study. However, the purpose of our study was to investigate the association between insulin resistance indices, including TyG and TG/HDL-C ratio, and abnormal liver function tests. Third, the FFQ in our study did not include information on calorie and nutrient intake, which could affect the association between abnormal liver function and insulin resistance index.

\section{Conclusions}

In conclusion, our study supported the evidence that the TyG index and TG/HDL-C ratio were strongly associated with the progression of abnormal liver function. The TyG index and TG/HDL-C ratio may be useful as non-invasive methods to predict the existence of abnormal liver function in the early stage. 
Supplementary Materials: The following are available online at https:/ / www.mdpi.com/article/ 10.3390/medicina58010004/s1, Table S1: Factor loading of three dietary patterns identified with principal component analysis. Table S2: Multivariable linear regression of liver function tests according to individual fasting blood glucose, triglyceride, and HDL-C levels. Table S3: Multivariable adjusted linear regression for liver function tests based on TyG index and TG/HDL-C ratio. Table S4: Multivariable adjusted logistic regression for abnormal liver function in different subgroups according to quintiles of TyG index and TG/HDL-C ratio. Figure S1: Linear prediction of TyG index with serum liver function. Figure S2: Linear prediction of TG/HDL-C ratio with serum liver function.

Author Contributions: Conceptualization, A.-L.K.; methodology, A.-L.K.; validation, A.-L.K., C.Y.H. and J.C.-J.C.; formal analysis, A.-L.K.; investigation, A.-L.K.; resources, C.-Y.H. and J.C.-J.C.; data curation, C.-Y.H. and H.-A.L.; writing-original draft preparation, A.-L.K., R.P. and A.-W.J.; writing-review and editing, R.P., A.-W.J., C.-Y.H. and J.C.-J.C. All authors have read and agreed to the published version of the manuscript.

Funding: This research received no external funding.

Institutional Review Board Statement: The study was conducted according to the guidelines of the Declaration of Helsinki, and the study protocols were approved by the Taipei Medical University Joint Institutional Review Board (TMU-JIRB N202010035).

Informed Consent Statement: Informed consent was obtained from all subjects involved in the study.

Data Availability Statement: The data that support the findings of this study are available from Mei Jau (M.J.) Health Management Institute, but restricted for research use only. The data are not publicly available. Data are available from the authors upon reasonable request and with permission of MJ Health Management Institute.

Acknowledgments: The authors thank Mei Jau Health Management (MJHM) Institute for collecting and providing their database available for this study.

Conflicts of Interest: The authors declare no conflict of interest.

\section{References}

1. Ballestri, S.; Zona, S.; Targher, G.; Romagnoli, D.; Baldelli, E.; Nascimbeni, F.; Roverato, A.; Guaraldi, G.; Lonardo, A. Nonalcoholic fatty liver disease is associated with an almost twofold increased risk of incident type 2 diabetes and metabolic syndrome. Evidence from a systematic review and meta-analysis. J. Gastroenterol. Hepatol. 2016, 31, 936-944. [CrossRef]

2. Wannamethee, S.G.; Shaper, A.G.; Lennon, L.; Whincup, P.H. Hepatic enzymes, the metabolic syndrome, and the risk of type 2 diabetes in older men. Diabetes Care 2005, 28, 2913-2918. [CrossRef] [PubMed]

3. Nolan, C.J.; Prentki, M. Insulin resistance and insulin hypersecretion in the metabolic syndrome and type 2 diabetes: Time for a conceptual framework shift. Diab. Vasc. Dis. Res. 2019, 16, 118-127. [CrossRef]

4. Han, H.-S.; Kang, G.; Kim, J.S.; Choi, B.H.; Koo, S.-H. Regulation of glucose metabolism from a liver-centric perspective. Exp. Mol. Med. 2016, 48, e218. [CrossRef]

5. Ahmed, Z.; Ahmed, U.; Walayat, S.; Ren, J.; Martin, D.K.; Moole, H.; Sean, K.; Sherri, Y.; Sonu, D. Liver function test in identifying patients with liver disease. Clin. Exp. Gastroenterol. 2018, 11, 301-307. [CrossRef]

6. Green, R.M.; Flamm, S. AGA technical review on the evaluation of liver chemistry tests. Gastroenterology 2002, 123, 1367-1384. [CrossRef]

7. Sesti, G.; Fiorentino, T.V.; Hribal, M.L.; Sciacqua, A.; Perticone, F. Association of hepatic insulin resistance indexes to nonalcoholic fatty liver disease and related biomarkers. Nutr. Metab. Cardiovasc. Dis. 2013, 23, 1182-1187. [CrossRef]

8. Kawaguchi, T.; Taniguchi, E.; Itou, M.; Sakata, M.; Sumie, S.; Sata, M. Insulin resistance and chronic liver disease. World J. Hepatol. 2011, 3, 99-107. [CrossRef]

9. Smith, B.W.; Adams, L.A. Nonalcoholic fatty liver disease and diabetes mellitus: Pathogenesis and treatment. Nat. Rev. Endocrinol. 2011, 7, 456-465. [CrossRef]

10. Loria, P.; Lonardo, A.; Anania, F. Liver and diabetes. A vicious circle. Hepatol. Res. 2013, 43, 51-64. [CrossRef]

11. De Silva, N.M.G.; Borges, M.C.; Hingorani, A.D.; Engmann, J.; Shah, T.; Zhang, X.; Luan, J.; Langenberg, C.; Wong, A.; Kuh, D.; et al. Liver Function and Risk of Type 2 Diabetes: Bidirectional Mendelian Randomization Study. Diabetes 2019, 68, $1681-1691$. [CrossRef]

12. Taylor, R.; Al-Mrabeh, A.; Zhyzhneuskaya, S.; Peters, C.; Barnes, A.C.; Aribisala, B.S.; Hollingsworth, K.G.; Mathers, J.C.; Sattar, N.; Lean, M.E.J. Remission of Human Type 2 Diabetes Requires Decrease in Liver and Pancreas Fat Content but Is Dependent upon Capacity for $\beta$ Cell Recovery. Cell Metabolism 2018, 28, 547-556.e543. [CrossRef]

13. Tam, C.S.; Xie, W.; Johnson, W.D.; Cefalu, W.T.; Redman, L.M.; Ravussin, E. Defining insulin resistance from hyperinsulinemiceuglycemic clamps. Diabetes Care 2012, 35, 1605-1610. [CrossRef] 
14. Wallace, T.M.; Levy, J.C.; Matthews, D.R. Use and abuse of HOMA modeling. Diabetes Care 2004, 27, 1487-1495. [CrossRef]

15. Yu, L.; Cai, Y.; Qin, R.; Zhao, B.; Li, X. Association between triglyceride glucose index and abnormal liver function in both urban and rural Chinese adult populations: Findings from two independent surveys. Medicine (Baltimore) 2019, 98, e18265. [CrossRef]

16. Radikova, Z. Assessment of insulin sensitivity/resistance in epidemiological studies. Endocr. Regul. 2003, 37, 189-194. [PubMed]

17. Simental-Mendía, L.E.; Rodríguez-Morán, M.; Guerrero-Romero, F. The product of fasting glucose and triglycerides as surrogate for identifying insulin resistance in apparently healthy subjects. Metab. Syndr. Relat. Disord. 2008, 6, 299-304. [CrossRef]

18. Abbasi, F.; Reaven, G.M. Comparison of two methods using plasma triglyceride concentration as a surrogate estimate of insulin action in nondiabetic subjects: Triglycerides $\times$ glucose versus triglyceride/high-density lipoprotein cholesterol. Metabolism 2011, 60, 1673-1676. [CrossRef]

19. Zhang, S.; Du, T.; Zhang, J.; Lu, H.; Lin, X.; Xie, J.; Yang, Y.; Yu, X. The triglyceride and glucose index (TyG) is an effective biomarker to identify nonalcoholic fatty liver disease. Lipids Health Dis. 2017, 16, 15. [CrossRef]

20. McLaughlin, T.; Reaven, G.; Abbasi, F.; Lamendola, C.; Saad, M.; Waters, D.; Simon, J.; Krauss, R.M. Is there a simple way to identify insulin-resistant individuals at increased risk of cardiovascular disease? Am. J. Cardiol. 2005, 96, 399-404. [CrossRef]

21. Salazar, M.R.; Carbajal, H.A.; Espeche, W.G.; Leiva Sisnieguez, C.E.; March, C.E.; Balbín, E.; Dulbecco, C.A.; Aizpurúa, M.; Marillet, A.G.; Reaven, G.M. Comparison of the abilities of the plasma triglyceride/high-density lipoprotein cholesterol ratio and the metabolic syndrome to identify insulin resistance. Diab. Vasc. Dis. Res. 2013, 10, 346-352. [CrossRef] [PubMed]

22. Vega, G.L.; Barlow, C.E.; Grundy, S.M.; Leonard, D.; DeFina, L.F. Triglyceride-to-high-density-lipoprotein-cholesterol ratio is an index of heart disease mortality and of incidence of type 2 diabetes mellitus in men. J. Investig. Med. 2014, 62, 345-349. [CrossRef]

23. Fiorentino, T.V.; Marini, M.A.; Succurro, E.; Andreozzi, F.; Sesti, G. Relationships of surrogate indexes of insulin resistance with insulin sensitivity assessed by euglycemic hyperinsulinemic clamp and subclinical vascular damage. BMJ Open Diabetes Res. Care 2019, 7, e000911. [CrossRef] [PubMed]

24. Department of Health Executive Yuan (Taiwan). Identification, Evaluation, and Treatment of Overweight and Obesity in Adults in Taiwan; Department of Health Executive Yuan: Taipei, Taiwan, 2003.

25. Chobanian, A.V.; Bakris, G.L.; Black, H.R.; Cushman, W.C.; Green, L.A.; Izzo Jr, J.L.; Jones, D.W.; Materson, B.J.; Oparil, S.; Wright Jr, J.T.; et al. Seventh report of the joint national committee on prevention, detection, evaluation, and treatment of high blood pressure. Hypertension 2003, 42, 1206-1252. [CrossRef] [PubMed]

26. Alberti, K.G.; Zimmet, P.Z. Definition, diagnosis and classification of diabetes mellitus and its complications. Part 1: Diagnosis and classification of diabetes mellitus provisional report of a WHO consultation. Diabet. Med. 1998, 15, 539-553. [CrossRef] [PubMed]

27. Liang, J.; Jiang, Y.; Huang, Y.; Song, W.; Li, X.; Huang, Y.; Ou, J.; Wei, Q.; Gu, J. The comparison of dyslipidemia and serum uric acid in patients with gout and asymptomatic hyperuricemia: A cross-sectional study. Lipids Health Dis. 2020, 19, 31. [CrossRef]

28. Levey, A.S.; Stevens, L.A.; Schmid, C.H.; Zhang, Y.L.; Castro, A.F., 3rd; Feldman, H.I.; Kusek, J.W.; Eggers, P.; Van Lente, F.; Greene, T.; et al. A new equation to estimate glomerular filtration rate. Ann. Intern. Med. 2009, 150, 604-612. [CrossRef]

29. Syauqy, A.; Hsu, C.Y.; Rau, H.H.; Chao, J.C. Association of dietary patterns, anthropometric measurements, and metabolic parameters with $\mathrm{C}$-reactive protein and neutrophil-to-lymphocyte ratio in middle-aged and older adults with metabolic syndrome in Taiwan: A cross-sectional study. Nutr. J. 2018, 17, 106. [CrossRef]

30. Limdi, J.K.; Hyde, G.M. Evaluation of abnormal liver function tests. Postgrad Med. J. 2003, 79, 307-312. [CrossRef]

31. Chen, S.; Guo, X.F.; Zhang, X.G.; Yu, S.S.; Yang, H.M.; Jiang, M.H.; Sun, G.Z.; Sun, Y.X. Association between elevated serum alanine aminotransferase and cardiometabolic risk factors in rural Chinese population: A cross-sectional study. Bmc Cardiovasc. Disor. 2015, 15. [CrossRef] [PubMed]

32. Syauqy, A.; Hsu, C.Y.; Rau, H.H.; Kurniawan, A.L.; Chao, J.C. Association of Sleep Duration and Insomnia Symptoms with Components of Metabolic Syndrome and Inflammation in Middle-Aged and Older Adults with Metabolic Syndrome in Taiwan. Nutrients 2019, 11. [CrossRef]

33. Kurniawan, A.L.; Hsu, C.Y.; Rau, H.H.; Lin, L.Y.; Chao, J.C. Dietary patterns in relation to testosterone levels and severity of impaired kidney function among middle-aged and elderly men in Taiwan: A cross-sectional study. Nutr. J. 2019, 18, 42. [CrossRef] [PubMed]

34. Zheng, R.; Du, Z.; Wang, M.; Mao, Y.; Mao, W. A longitudinal epidemiological study on the triglyceride and glucose index and the incident nonalcoholic fatty liver disease. Lipids Health Dis. 2018, 17, 262. [CrossRef] [PubMed]

35. Yki-Järvinen, H. Non-alcoholic fatty liver disease as a cause and a consequence of metabolic syndrome. Lancet Diabetes Endocrinol 2014, 2, 901-910. [CrossRef]

36. Guo, W.; Lu, J.; Qin, P.; Li, X.; Zhu, W.; Wu, J.; Xu, N.; Zhang, Q. The triglyceride-glucose index is associated with the severity of hepatic steatosis and the presence of liver fibrosis in non-alcoholic fatty liver disease: A cross-sectional study in Chinese adults. Lipid Health Dis. 2020, 19, 218. [CrossRef]

37. Gastaldelli, A.; Folli, F.; DeFronzo, R.A. The product of triglycerides and glucose as index of insulin resistance. Validation in the SAM study. J. Clin. Endocrinol. Metab. 2010, 95, 3351.

38. Adiels, M.; Westerbacka, J.; Soro-Paavonen, A.; Häkkinen, A.-M.; Vehkavaara, S.; Caslake, M.J.; Packard, C.; Olofsson, S.-O.; Yki-Järvinen, H.; Taskinen, M.R.; et al. Acute suppression of VLDL 1 secretion rate by insulin is associated with hepatic fat content and insulin resistance. Diabetologia 2007, 50, 2356-2365. [CrossRef] [PubMed] 
39. Fukuda, Y.; Hashimoto, Y.; Hamaguchi, M.; Fukuda, T.; Nakamura, N.; Ohbora, A.; Kato, T.; Kojima, T.; Fukui, M. Triglycerides to high-density lipoprotein cholesterol ratio is an independent predictor of incident fatty liver; a population-based cohort study. Liver Int. 2016, 36, 713-720. [CrossRef] [PubMed]

40. Fan, N.; Peng, L.; Xia, Z.; Zhang, L.; Song, Z.; Wang, Y.; Peng, Y. Triglycerides to high-density lipoprotein cholesterol ratio as a surrogate for nonalcoholic fatty liver disease: A cross-sectional study. Lipid Health Dis 2019, 18, 39. [CrossRef]

41. Chen, Z.; Qin, H.; Qiu, S.; Chen, G.; Chen, Y. Correlation of triglyceride to high-density lipoprotein cholesterol ratio with nonalcoholic fatty liver disease among the non-obese Chinese population with normal blood lipid levels: A retrospective cohort research. Lipid Health Dis 2019, 18, 1-7. [CrossRef]

42. Kim, J.-S.; Kang, H.-T.; Shim, J.-Y.; Lee, H.-R. The association between the triglyceride to high-density lipoprotein cholesterol ratio with insulin resistance (HOMA-IR) in the general Korean population: Based on the National Health and Nutrition Examination Survey in 2007-2009. Diabetes Res. Clin Pract 2012, 97, 132-138. [CrossRef] [PubMed]

43. Sonmez, A.; Yilmaz, M.I.; Saglam, M.; Unal, H.U.; Gok, M.; Cetinkaya, H.; Karaman, M.; Haymana, C.; Eyileten, T.; Oguz, Y.; et al. The role of plasma triglyceride/high-density lipoprotein cholesterol ratio to predict cardiovascular outcomes in chronic kidney disease. Lipid Health Dis 2015, 14, 29. [CrossRef]

44. Rizzo, M.; Berneis, K. Who needs to care about small, dense low-density lipoproteins? Int J. Clin Pract 2007, $61,1949-1956$. [CrossRef] [PubMed]

45. Nikolic, D.; Katsiki, N.; Montalto, G.; Isenovic, E.R.; Mikhailidis, D.P.; Rizzo, M. Lipoprotein subfractions in metabolic syndrome and obesity: Clinical significance and therapeutic approaches. Nutrients 2013, 5, 928-948. [CrossRef]

46. Christou, G.A.; Kiortsis, D.N. Adiponectin and lipoprotein metabolism. Obes Rev. 2013, 14, 939-949. [CrossRef] [PubMed] 